\title{
Insect Repellency and Crop Productivity of Essential Oil Films ${ }^{1}$
}

\author{
Jin Gu $\mathrm{KIM}^{2} \cdot$ Seok Gyu $\mathrm{KANG}^{3} \cdot \mathrm{Md}$ Munir MOSTAFIZ ${ }^{4} \cdot$ Jeong Min $\mathrm{LEE}^{5}$ • \\ Kyeong-Yeoll LEE ${ }^{4}$ Tae Kyung $\mathrm{HWANG}^{6} \cdot$ Jin Taeg $\mathrm{LIM}^{7} \cdot$ \\ Soo Yeon $\mathrm{KIM}^{8} \cdot$ Won Hee LEE (D) ${ }^{5, \dagger}$
}

\begin{abstract}
The purpose of this study was to determine the effects of coniferous essential oils (EOs) blended films on insect repellence and crop productivity. Low-density polyethylene (LDPE) film is widely used, especially in agriculture and for food packaging. Ethylene vinyl acetate was blended with LDPE to reduce volatilization of EOs. An EO from Japanese cypress (Chamaecyparis obtusa) was incorporated into the blend film to conduct field research on antimicrobial and insect repellent properties. Among the various concentrations of EO, the highest concentration (2.5\%) showed the highest efficiency in terms of pesticidal activity. The ability to inhibit microbial growth can be explained by the lipophilic properties of the EO component, and many studies have already demonstrated this. Agricultural films containing all types of EO have been tested on various crops such as chili, cucumber, Korean melon and have been able to verify their effectiveness in avoiding pests and increasing yields. From these results, it was found that it is reasonable to use a modified film such as a composite film containing an EO for agriculture. Thus, the modified film containing EO has undoubtedly shown impressive potential for reducing the use of pesticides in a variety of ways, not only for agricultural mulching film but also for food and agricultural product packaging. This product is an environmentally friendly chemical and is safe for agricultural and industrial and food packaging applications, among others. In particular, the use of agricultural films significantly reduces the use of pesticides, suggesting that farmers can increase their incomes by reducing working hours and costs, and increasing production.
\end{abstract}

Keywords: essential oil, EVA, LDPE, low pesticides, insect repellency, environmentally friendly

\footnotetext{
${ }^{1}$ Date Received December 2, 2019, Date Accepted January 15, 2020

2 Department of Physical Education, Kyungpook National University, Daegu 41566, Republic of Korea

3 Dongdaegu Agricultural Cooperative, 2487, Dalgubeol-daero, Suseong-gu, Daegu, Republic of Korea

${ }^{4}$ School of Applied Biosciences, Kyungpook National University, Daegu 41566, Republic of Korea

${ }^{5}$ School of Forest Sciences and Landscape Architecture, Kyungpook National University, Daegu 41566, Republic of Korea

${ }^{6}$ Gunwigun Agriculture Technology Center. Gunwigun Gyeongbuk 39026, Republic of Korea

${ }^{7}$ Agricultural Information Service Ltd., 3 Gongdan-ro, Buk-gu, Daegu 41496, Republic of Korea

${ }^{8}$ Gyeongsangbuk-do Agricultural Research \& Extension Services, Daegu 41404, Republic of Korea

$\dagger$ Corresponding author: Won Hee LEE (e-mail: leewh@knu.ac.kr, ORCID: 0000-0002-8042-1248)
} 
Jin Gu KIM • Seok Gyu KANG • Md Munir MOSTAFIZ • Jeong Min LEE • Kyeong-Yeoll LEE •

Tae Kyung HWANG $\cdot$ Jin Taeg LIM $\cdot$ Soo Yeon KIM $\cdot$ Won Hee LEE

\section{INTRODUCTION}

With the growing interest in environmental issues and human health, research on easily biodegradable and environmentally friendly pesticides or pest control agents is increasingly popular. Plants are known to suppress the invasion of pests by emitting a scent as a mechanism to protect their bodies. This is a plant essential oil (EO) we often call phytoncide. Until now, research on the antimicrobial components of conifer EOs for use as raw materials for cosmetics has been conducted by many researchers. (Cheng et al., 2005; Kang et al., 1993).

There have been various studies of EOs on insect repelling. Studies on the toxicity of cedar EOs to silverfish show very good pest repelling effects at low concentrations (Wang et al., 2006).

Currently, most agricultural mulching films are thermoplastics based on olefin polymers such as highdensity polyethylene, low-density polyethylene (LDPE), polypropylene, and linear low-density polyethylene. These tend to outperform other types of materials due to low cost, durability, light weight, and high corrosiveness.

LDPE is one of the most suitable materials for wrapping and packing agrifood products due to its high flexibility and toughness. However, one of the major drawbacks of LDPE used in agricultural mulching films is the lack of antimicrobial and insect-repellent properties. In general, the study of mulching in agriculture mainly includes the durability of the film, the environment (Wang et al., 2004), soil warming and moisture conservation effect (Liu et al., 2014) and the decomposition (Scarascia-Mugnozza et al., 2006). However, there is no research on whether mulching suppresses insects.

Various antibacterial agents such as organic acids, inorganic gases, bacteriocins, metals such as silver, etc. have been proposed, but there are difficult problems with their use. Nevertheless, the use of synthetics or chemicals as antimicrobials in food packaging has raised concerns among consumers as well as environmental issues. Instead of using synthetic chemicals, natural plant extracts from trees are thought to be a generally safe alternative for improving antimicrobial and insect repellent properties in food packaging such as LDPE films.

In the field of wood engineering, the research on film mainly involves the effect of the addition amount of nanocellulose and the effect of starch on strength and thermal properties (Lee et al., 2014). There have been studies on the adhesive performance of plywood according to the lamination method of film (Kang et al., 2017), printability of coated paper (Lee, 1994), mechanical and thermal properties of composite film using cellulose nanofibers (Lee et al., 2015), and highstrength nanopaper and polymer composite film (Lee et al., 2011).

Regarding antimicrobial activity, there have been studies on the physiological activity of tree extracts (Oh et al., 2001), the extract of magnolia (Kim, 1999), the antimicrobial activity of EO of coniferous leaves (Lee et al., 2002), antimicrobial activity against dermatophytes on minus (Min, 1998; Jang, 2005), antimicrobial activity of tree barks (Lee et al., 2003), antimicrobial and antioxidant activity of oak extracts (Yang et al., 2000), antimicrobial and antioxidant activities of extracts from wild cherry heartwood extracts (Lee et al., 2001; 2003), antimicrobial and antioxidant activities of zelkova heartwood (Lee et al., 2000; Lee et al., 2004), studies on the isolation and chemical structure of chemical composition and mycobacterium of elm root bark (Eom et al., 2003), antimicrobial and antioxidant activity of magnolia and plants (Lee et al., 2010), antimicrobial activity against strains of gingko biloba extract (Yang et al., 2008), and the availability of active and agricultural chemicals (Lee et al., 2010).

Insect repellents, on the other hand, have been used 
primarily in wood preservation. There have been studies on the properties of the flame retardant composite preservation treatment of microwave-heated wood (Lim et al., 2013) and on the interfacial electrochemical properties of the fixation properties of new water-soluble preservative insect repellents (Kim, 1996). However, there have been no domestic studies on insect-repellent effects of EOs films.

In literature, it is generally known that the various natural components of herbal extracts exhibit excellent antimicrobial activity, such as clover leaf oil, sweet basil oil, and cinnamon peel oil, including tree EOs (Lee et al., 2015).

There has also been a review of food packaging (Appendinia et al., 2002). That paper reviews various types of antimicrobial polymers developed for food contact, commercial applications, test methods, regulations, and future trends. Particular emphasis is placed on the disadvantages of each technology. Their work has focused on incorporating bioactive agents, including tree EOs, directly into polymers among many ways. This method has been applied commercially to drug and pesticide delivery, household food, textiles, surgical implants, and other biomedical devices.

In Wang's pilot study (Wang et al., 2006), EOs extracted from the leaves of Cryptomeria japonica were examined to test their properties as a silverfish repellent and insecticide. Their study demonstrates the toxic effects of the EO of $C$. japonica on silverfish. In the non-treated group $\left(0.00 \mathrm{mg} / \mathrm{cm}^{3}\right)$, silverfish survived with active motion during the test period. When the different amounts of EO were added to the test dishes, a dose-dependent insecticidal effect was observed in the test chambers. All the test silverfish were killed at the highest dosage $\left(0.16 \mathrm{mg} / \mathrm{cm}^{3}\right)$ after 10 hrs of exposure. The percentage mortalities at other concentrations of EO were $40.0 \%$ (dosage $0.08 \mathrm{mg} / \mathrm{cm}^{3}$ ) and $10.0 \%$ (dosage $0.02 \mathrm{mg} / \mathrm{cm}^{3}$ ).

Since many studies on the EOs of cedar and cypress
Table 1. Solubility parameters of LDPE, EVA, and major constituents of EOs (Peppas et al., 1997).

\begin{tabular}{|c|c|}
\hline Material/chemical & Solubility parameter $\left(\mathrm{MPa}^{1 / 2}\right)$ \\
\hline LDPE & 17.6 \\
\hline EVA & 20.9 \\
\hline Eugenol & 23.3 \\
\hline Linalool & 20.3 \\
\hline Cinnamaldehyde & 26.01 \\
\hline
\end{tabular}

Note: Cinnamaldehyde can mix with ethanol, the solubility parameter of which is 26.0 at any ratio (He et al., 2009; Barton, 1975).

trees have been conducted, the main components of EOs and their structures are generally well known (Cheng et al., 2005; Yang et al., 2007). The reason why cypress is used in this study because it is well known that research on this tree is sufficient and has the effect of avoiding insects (Lee et al., 2015).

Since EOs can easily evaporate at ambient temperature, ethylene vinyl acetate (EVA) was mixed with LDPE to reduce the evaporation rate of these EOs, as shown in the study by Suppakul et al. (2011).

As shown in Table 1, the method of reducing the loss of active antimicrobial agents during the manufacture of LDPE films was studied because the solubility parameters of EVA were between LDPE and EO. EVA can partially attach EO in the polymer matrix (Kasemsan et al., 2014; He, 2009; Peppas et al., 1997; Barton, 1975).

Therefore, this study examined the pest killing effect of tree EO-impregnated films and the efficacy of agricultural products in the field.

\section{MATERIALS and METHODS}

\subsection{Materials and essential oil preparation}

LDPE with MFI of $5.20 \mathrm{~g} / 10 \mathrm{~min}$ was purchased from Woosung chemical Ltd., Korea. Ethylene vinyl acetate (EVA) with MFI of $2.9 \mathrm{~g} / 10 \mathrm{~min}$ was obtained from SK chemicals, Korea. Japanese cypress (Chamaecyparis obtusa) EO was obtained from fresh 
Jin Gu KIM • Seok Gyu KANG • Md Munir MOSTAFIZ • Jeong Min LEE • Kyeong-Yeoll LEE •

Tae Kyung HWANG $\cdot$ Jin Taeg LIM $\cdot$ Soo Yeon KIM $\cdot$ Won Hee LEE

leaves by steam distillation using a Clevenger-type apparatus (C-3928-MBAO Pyrex, USA).

\subsection{Compounding procedures}

LDPE incorporated with 10 wt\% of EVA and pure EVA were each melt-compounded in a co-rotating twin-screw extruder at a screw speed of $70 \mathrm{rpm}$. Due to air-cooling, the temperature of the extruder ranged from $100{ }^{\circ} \mathrm{C}$ in the die zone to prevent loss of plant extracts and to maintain a low melt flow index in the mixture. The extrudate was then removed from the twin-screw extruder and ground to pelletize. This is called masterbatch (MB). Likewise, LDPE incorporated with $10 \mathrm{wt} \%$ of EVA containing several kinds of cypress oil (0.5-7.5 wt\% for master batch) was prepared under the same conditions as in the above paragraphs without the presence of EOs.

\subsection{Films preparation}

A 30- $\mu$ m-thick film was made by blown film extruder. The temperature profile in all zones was $160{ }^{\circ} \mathrm{C}$ at a motor speed of 250 rpm. Films containing EOs should be stored once in vinyl to minimize the loss of insect repellent by evaporation and at ambient temperature before testing.

\subsection{Bioassay of mortality}

Bioassay was performed in the entomology laboratory at Kyungpook National University. Experiments were done with pests such as whiteflies and bean bugs. The pest mortality experiments were carried out with films made by varying the concentration of tree EOs. The production conditions of the master batch made by controlling the amount of wood EO and the manufacturing condition of the film fabric were very complicated, and the mortality effect of pests was tested for each condition using glass cylinders and petri dishes. In this study, the effect of plastic film with $0.5 \%$ EO on the mortality of whitefly (Bemisia tabaci) was examined. Twenty-five individuals were tested in a chamber at $20{ }^{\circ} \mathrm{C}$ in $65 \%$ relative humidity. Bioassay was conducted with adults of Bemisia tabaci in three ways using a glass cylinder $(15 \mathrm{~cm}$ height $\times 1.5 \mathrm{~cm}$ diameter), two different size of Petri dishes $(15 \mathrm{~cm}$ $\mathrm{D} \times 3 \mathrm{~cm} \mathrm{H})$, and $(9.5 \mathrm{~cm} \mathrm{D} \times 4 \mathrm{~cm} \mathrm{H})$. The position of the film was adjusted in three ways as follows.

Experiment 1: Plastic film (15 $\mathrm{cm} \mathrm{H}$ or $15 \mathrm{~cm} \mathrm{D)}$ was placed at the bottom of the inside of the Petri dish assay. Experiment 2: Plastic film $(15 \mathrm{~cm} \mathrm{H}$ or $15 \mathrm{~cm} \mathrm{D)}$ was wrapped inside the glass cylinder. Experiment 3: Plastic film $(9.5 \mathrm{~cm} \mathrm{D} \times 4 \mathrm{~cm} \mathrm{H})$ covered the tops of petri dishes.

\subsection{Field test}

The experiments in the field were carried out at the Gunwigun Agricultural Technology Center (36.181403, 128.592552) and the farmhouse (35.880297, 128.178027) of Habin-myeon, Dalseong-gun Gyeongbuk province. Cucumbers, chili, cabbages, and yellow melons were visually examined for pest infestation status and yield.

\subsection{GC-MS analysis of LDPE/EVA blended films}

The EO components were identified using SPME (solid-phase microextraction) method with an Agilent 7890B GC \& 5975C MSD equipped with a TC-5 capillary column (DB-WAX 60m $\times 0.25 \mathrm{~mm} \times 0.25 \mathrm{um}$, Inlet temp $250{ }^{\circ} \mathrm{C}$ ). Helium was used as the carrier gas at a flow rate of $1.2 \mathrm{~mL} / \mathrm{min}$, and the column temperature was programmed to hold initially at $40{ }^{\circ} \mathrm{C}$ (2 minutes hold) and then increase at a rate of $2{ }^{\circ} \mathrm{C} / \mathrm{min}$ to $220^{\circ} \mathrm{C}$ and then increase at a rate of $20{ }^{\circ} \mathrm{C} / \mathrm{min}$ to $240{ }^{\circ} \mathrm{C}$ (total 98 minutes hold). The injector and detector temperatures were set at 200 and $240{ }^{\circ} \mathrm{C}$, respectively. One microliter samples of the $1 \mathrm{~mL} / \mathrm{min}$ sample were injected in the split mode (1:20 split ratio). Mass spectra were recorded in the range of $35 \sim 500 \mathrm{~m} / \mathrm{z}$ at a scan rate of 2 scans/seconds, with an ionization energy of 
$70 \mathrm{eV}$. The relative concentration of each compounding essential oil was quantified based on the peak area integrated by the analysis program.

Kasemsan et al. (2014) found that LDPE and EVA exhibited single endothermic peaks of $107.70{ }^{\circ} \mathrm{C}$ and $85.99{ }^{\circ} \mathrm{C}$, respectively, representing the melting temperatures of the crystalline phases from the DSC thermograms obtained for LDPE, EVA, and mixtures thereof. In a study by Faker et al. (2008), this was shown to indicate incompatibility of LDPE and EVA crystals. We also found that LDPE-EVA blend films can be mixed, but the ethylene portion in the backbone chain of LDPE and EVA is compatible. Another reason for our choice is that blends containing $10 \%$ wt of EVA retain more linal than other blends at some point. Since the amount of resin, the amount of pores, and the size of the film were found to be inversely proportional, 10\% EVA resin was used here. The components of the control film and the EO-impregnated LDPE / EVA blend films were investigated.

\section{RESULTS and DISCUSSION}

EOs are complex mixtures of various compounds.
Each of these compounds contributes to the beneficial or disadvantageous activity of the EO. For this reason, when investigating the viability of a particular application, it is necessary to explore the entire composition of EOs. Equipped with capillary columns, GC-MS is the most commonly used technology to understand the chemical composition of EOs. Fig. 1 and Table 2 show the results of GC-MS analysis on vinyl impregnated with EO of the cypress leaf. $\alpha$-Pinene (6.32\%), $\rho$ Cymene-8-ol (3.26\%), 3-Carene (3.22\%), Terpinen-4-ol (2.74\%), Butylated hydroxytoluene (2.18\%), $\alpha$-Cyclohexanemethanol (1.77\%), Selinan (1.70\%), and $\beta$ -Cadinene (1.38\%) were the most abundant. GC analysis was performed at $2.5 \%$ concentration.

In this study, six different concentrations $(0,0.1,0.2$, $0.3,0.4,0.5 \%$ ) were tested in the experiment on the effect of vegetable coating on the mortality of nymph (Fig. 2). The second instagram $(n=5)$ was released from the glass cylinder and the cylinder was sealed with parafilm. Mortality was assessed up to $72 \mathrm{~h}$ at 24-h intervals. During the experiment, over $80 \%$ of dead insects were found in over $0.4 \%$ of high capacity test cylinders (Fig. 3).

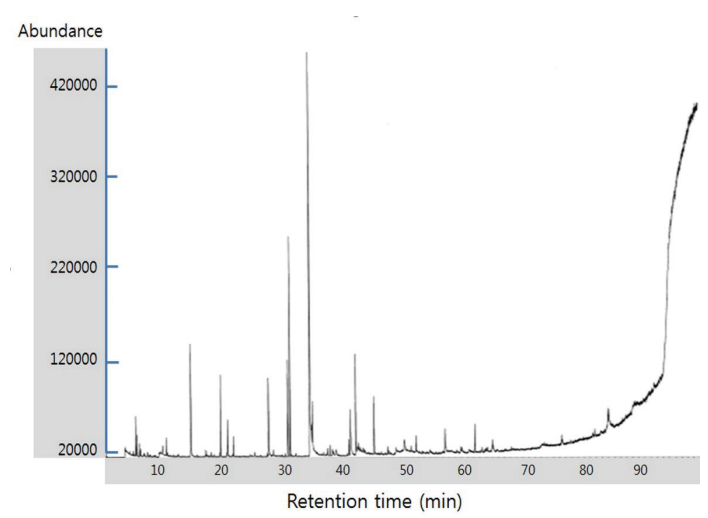

(a) Control film without essential oil.

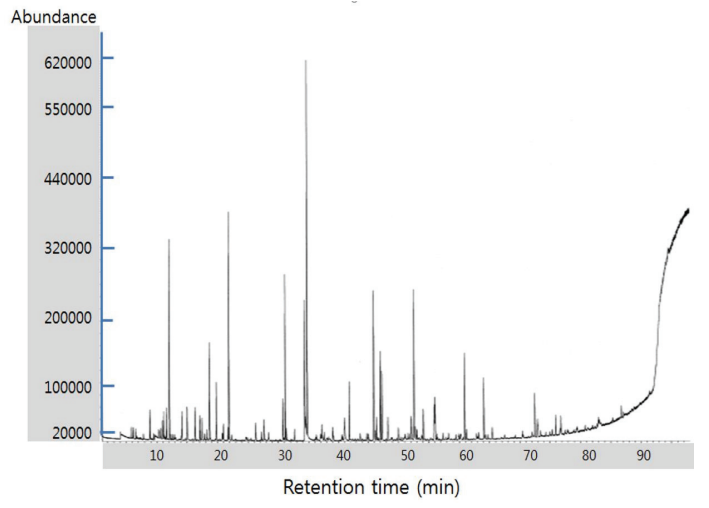

(b) Film with $2.5 \%$ essential oil.

Fig. 1. Total ion chromatograms of the Chamaecyparis obtusa leaf essential oil. (a) Film without essential oil; (b) Essential oil emission in the film extracted by solid-phase microextraction. 
Jin Gu KIM • Seok Gyu KANG • Md Munir MOSTAFIZ • Jeong Min LEE - Kyeong-Yeoll LEE •

Tae Kyung HWANG $\cdot$ Jin Taeg LIM $\cdot$ Soo Yeon KIM $\cdot$ Won Hee LEE

Table 2. Chemical composition of fragrance of control and modification vinyl

\begin{tabular}{|c|c|c|c|c|}
\hline Material & Compounds & Retention time (min) & $\%$ & Emission (\%) \\
\hline \multirow{3}{*}{ Control } & 2-Amino-6-methylbenzoic acid & 56.348 & 1.40 & \multirow{3}{*}{4.09} \\
\hline & Benzeneethanol & 64.063 & 0.73 & \\
\hline & 2,4-Di-tert-butylphenol & 82.932 & 1.96 & \\
\hline \multirow{22}{*}{$\begin{array}{c}10 \% \text { EVA } \\
\text { resin-impregnated } \\
\text { vinyl with } 2.5 \% \\
\text { essential oil }\end{array}$} & $\alpha$-Pinene & 12.082 & 6.32 & \multirow{22}{*}{33.19} \\
\hline & Camphene & 14.137 & 0.97 & \\
\hline & Sabinene & 17.105 & 0.83 & \\
\hline & Ethylbenzene & 17.426 & 0.85 & \\
\hline & p-Xylene & 18.224 & 0.44 & \\
\hline & 3-Carene & 18.710 & 3.22 & \\
\hline & Cyclohexen & 21.726 & 0.44 & \\
\hline & o-Cymene & 26.278 & 0.69 & \\
\hline & Cyclohexen & 27.203 & 0.38 & \\
\hline & $\beta$-Elemene & 46.390 & 0.85 & \\
\hline & Terpinen-4-ol & 47.292 & 2.74 & \\
\hline & Thujopsene & 48.246 & 0.94 & \\
\hline & Naphthalene & 52.107 & 1.00 & \\
\hline & $\alpha$-Terpineol & 52.765 & 0.49 & \\
\hline & $\alpha$-Muurolene & 54.101 & 1.20 & \\
\hline & $\beta$-Cadinene & 55.925 & 1.38 & \\
\hline & Selinan & 56.038 & 1.70 & \\
\hline & $\rho$-Cymene-8-ol & 60.896 & 3.26 & \\
\hline & Butylated hydroxytoluene & 64.074 & 2.18 & \\
\hline & $\alpha$-Cyclohexanemethanol & 72.475 & 1.77 & \\
\hline & 2,4-heptadiene & 75.958 & 0.82 & \\
\hline & 1H-Imidazole & 76.821 & 0.72 & \\
\hline
\end{tabular}

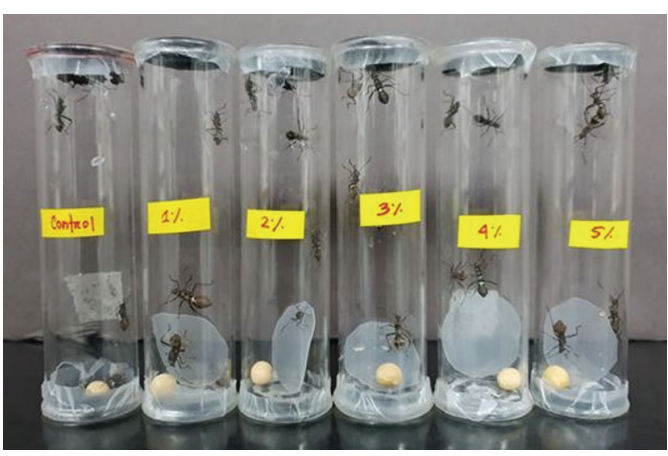

Fig. 2. Bioassay was performed with a second instar nymphs of $R$. pedestris using a glass cylinder (15 $\mathrm{cm}$ in height $\times 1.5 \mathrm{~cm}$ in diameter). A $2.5 \mathrm{~cm}$ diameter phytoncide-coated film was included in a glass cylinder.

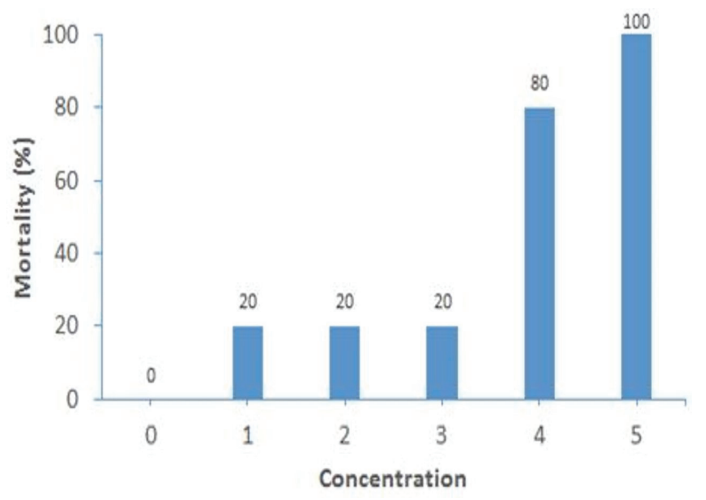

Fig. 3. Relationships between insect mortality (\%) and essential oil concentration $(\times 0.1 \%)$. 


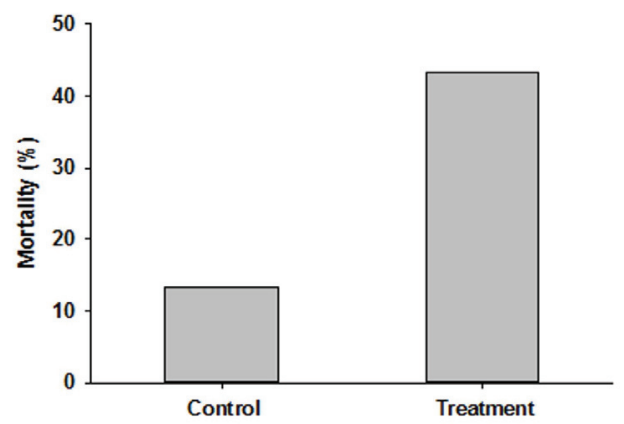

Fig. 4-a. Mortality after $24 \mathrm{~h}$.

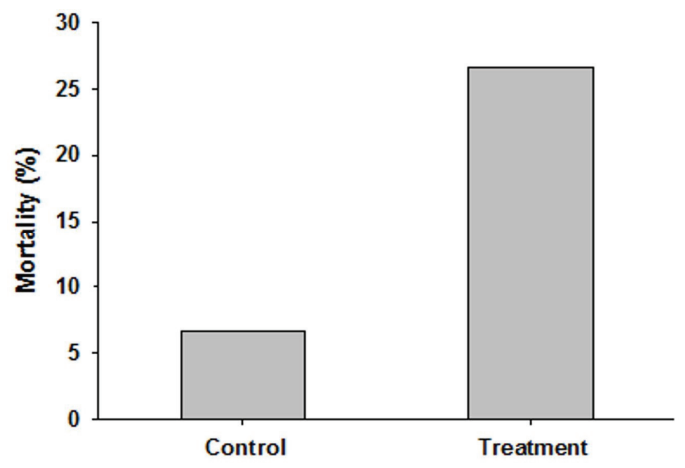

Fig. 5-a. Mortality after 24 h.

In Fig. 4-a, adults $(\mathrm{n}=30)$ were released into the glass cylinder or petri dishes, which were sealed with parafilm. Mortality was assessed at $24 \mathrm{~h}$ post-treatment. In Experiment 1, where the plastic film was placed on the inner bottom of the Petri dish analysis, the mortality rates of white flies after treatment for $24 \mathrm{~h}$ were $13.3 \%$ in the control and $43.3 \%$ in the film (Fig. 4-b). Thus, corrected mortality is $30 \%$. In Experiment 2, in Fig. 5-b, where the plastic film was wrapped inside the glass cylinder, the mortality rates of white flies after $24 \mathrm{~h}$ treatment were $6.7 \%$ in the control and $26.7 \%$ in the impregnated film, so the corrected mortality was 20\% (Fig. 5-a). In Experiment 3 (Fig. 6-b), the mortality rates of white flies after treatment for $24 \mathrm{~h}$ when the plastic film was covered on the top

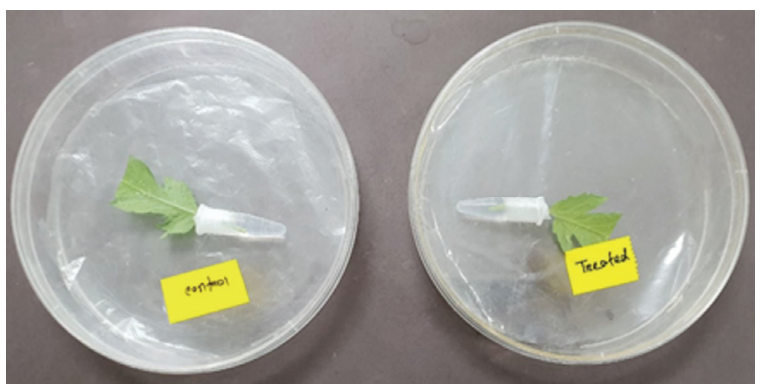

Fig. 4-b. A $15 \mathrm{~cm}$ diameter plastic film was added into the petri dish $(15 \mathrm{~cm}$ diameter $\times 3 \mathrm{~cm}$ height).

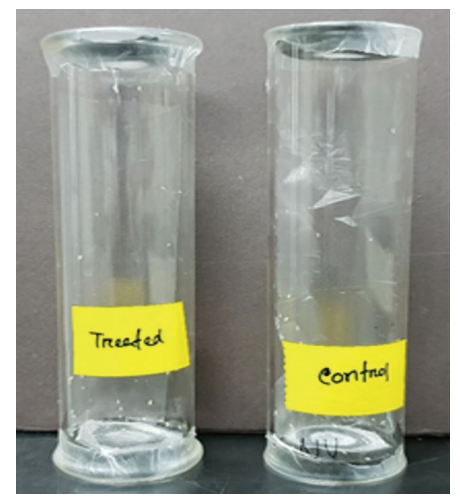

Fig. 5-b. Plastic film was wrapped inside of the glass cylinder $(15 \mathrm{~cm}$ height $\times 1.5 \mathrm{~cm}$ diameter $)$.

of the petri dish were $3.7 \%$ for the control, $16.7 \%$ for the EO-impregnated vinyl, and $13 \%$ for the corrected mortality (Fig. 6-a). As a result of experiments varying the concentration of $\mathrm{EO}$ in the impregnated film, it was found that the insecticidal effect of bean bug appeared in more than 1.5\%. As shown in Fig. 7, the mortality rate of all was $60 \%$ after $24 \mathrm{~h}$ at $1.5 \%$ concentration or higher. After 4 days, $100 \%$ of all insects died. Unfortunately, there is no previous study on the effects of mulching films on pest control, so the results of this paper cannot be discussed in comparison with previous studies.

Therefore, a film of $2.5 \%$ EO concentration was prepared and provided to a demonstration farm to perform field experiments (Lee et al., 2019). In the Kunwi 
Jin Gu KIM • Seok Gyu KANG • Md Munir MOSTAFIZ • Jeong Min LEE - Kyeong-Yeoll LEE •

Tae Kyung HWANG $\cdot$ Jin Taeg LIM $\cdot$ Soo Yeon KIM $\cdot$ Won Hee LEE

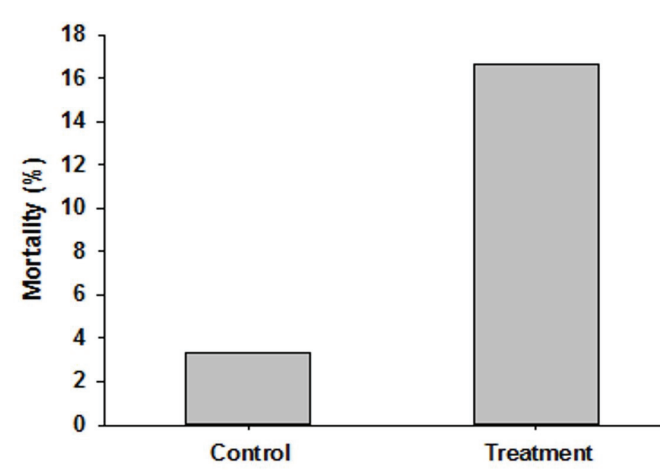

Fig. 6-a. Mortality after 24 h.

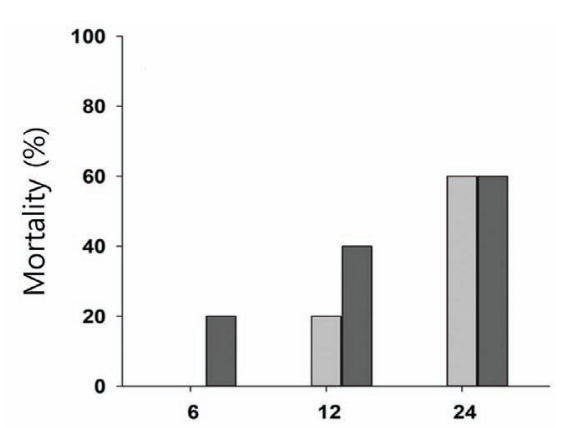

Fig. 7. Effect of essential oil film on the mortality of bean bug (Riptortus pedestris).

Note: Essential oil 1.5\% ( $\square$ ) and 2.5\% concentration.

Agricultural Technology Center in Gyeongbuk, the yield of cucumbers using functional films increased $11 \%$ due to improved productivity and marketability compared to the control (Fig. 8). In addition, the incidence of bacterial diseases on microorganisms was reduced, and the growth period was 20 days longer than that of the control group, leading to increased income (Hwang et al., 2019). As a result of application to the chili field, it was confirmed qualitatively that functional film applied chili production increased because anthrax was produced in the control group (Fig. 9). Currently, empirical experiments are being carried out on melon, garlic, onion, and cucumber farms.

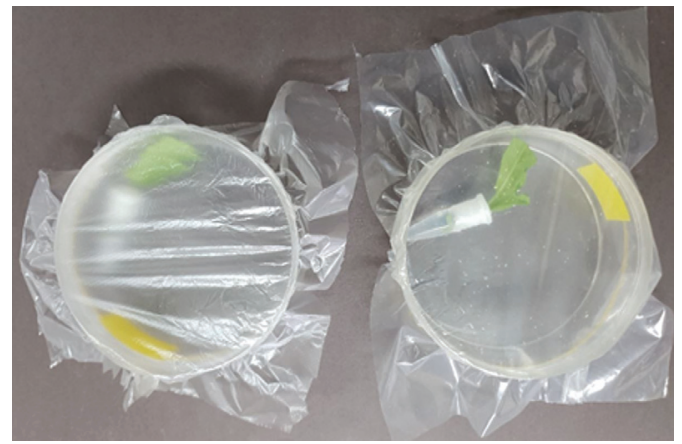

Fig. 6-b. Plastic film was covered into the petri dish (9.5 cm diameter $\times 4 \mathrm{~cm}$ height).

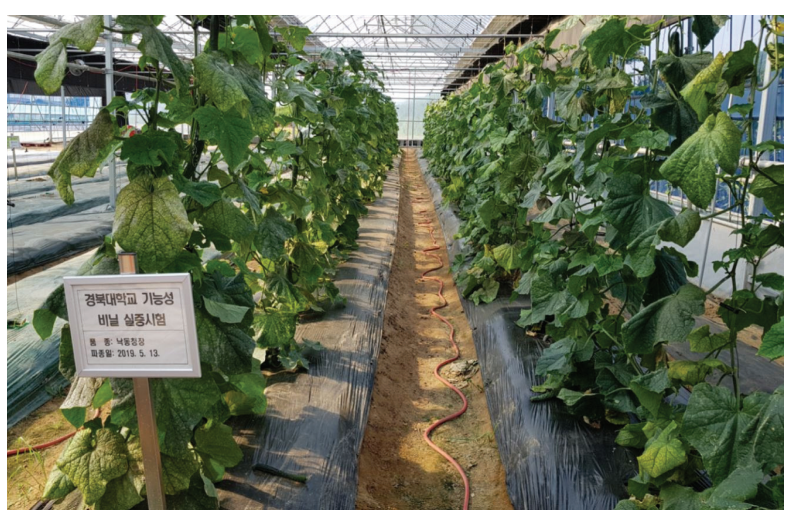

Fig. 8. Cucumber Experiment at Kunwigun Agricultural Technology Center.

Based on the results obtained in this pilot study, we concluded that EOs are likely to be developed in the leaves of coniferous trees for use as reagents to prevent damage by insects and microorganisms. This product is an environmentally friendly chemical and is safe for agricultural, industrial, and food packaging applications, among others. In conclusion, the findings of this study suggested that the use of agricultural mulching films (Figs. 8 and 9) possibly can reduce the use of pesticide, suggesting that farmers can increase their incomes by reducing working hours and costs, and increasing production. Furthermore, consumers can also use safe produce. 

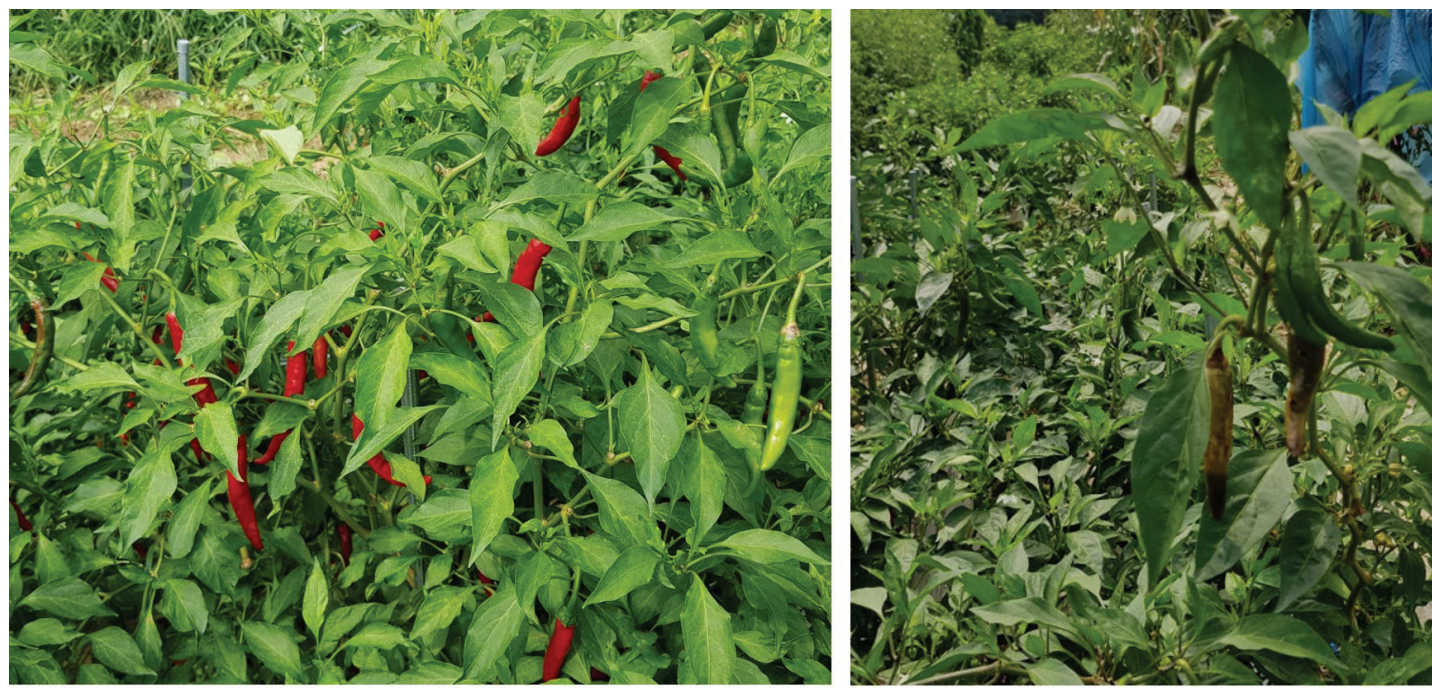

Fig. 9. Insect repellent film (left) and general film (anthrax damage in right) in chili farm.

\section{CONCLUSION}

This study examined the pest killing effect of tree EO-impregnated films and the efficacy of agricultural products in the field. An EO from Japanese cypress (Chamaecyparis obtusa) was incorporated into the blend film to conduct field research on antimicrobial and insect repellent properties. Among the various concentrations of EO, the highest concentration (2.5\%) showed the highest efficiency in terms of pesticidal activity. Agricultural films containing all types of EO have been tested on various crops such as chili, cucumber, Korean melon and have been able to verify their effectiveness in avoiding pests and increasing yields. From these results, it was found that it is reasonable to use a modified film such as a composite film containing an EO for agriculture. Thus, the modified film containing EO has undoubtedly shown impressive potential for reducing the use of pesticides in a variety of ways, not only for agricultural mulching film but also for food and agricultural product packaging. This product is an environmentally friendly chemical and is safe for agricul- tural and industrial and food packaging applications, among others. Therefore, the findings of this study suggested that the use of agricultural mulching films possibly can reduce the use of pesticide, suggesting that farmers can increase their incomes by reducing working hours and costs, and increasing production. Furthermore, consumers can also use safe produce.

\section{REFERENCES}

Appendinia, P., Hotchkissb, J.H. 2002. Review of antimicrobial food packaging. Innovative Food Science \& Emerging Technologies 3: 113126.

Barton A.F.M. 1975. Solubility parameters. Chemical Reviews 75(6): 731-753.

Cheng, S.S., Lin, H.Y., Chang, S.T. 2005. Chemical composition and antifungal activity of essential oil from different tissues of Japanese cedar (Cryptomeria japonica). Journal of Agricultural Food Chemistry 53: 614-619.

Choi, Y.J., Lee, H.J., Lee, S.S., Choi, D.H. 2003. Studies on biological activity of wood extractives 
Jin Gu KIM • Seok Gyu KANG • Md Munir MOSTAFIZ • Jeong Min LEE - Kyeong-Yeoll LEE •

Tae Kyung HWANG $\cdot$ Jin Taeg LIM $\cdot$ Soo Yeon KIM $\cdot$ Won Hee LEE

(X)- Antifungal compounds of Hovenia dulcis. Journal of the Korean Wood Science and Technology 31(1): 1-9.

Faker, M., Razavi, A.M.K., Ghaffari, M., Seyyedi, S.A. 2008. Rheology, morphology and mechanical properties of polyethylene/ethylene vinyl acetate copolymer (PE/EVA) blends. European Polymer Journal 44(6): 1834-1842.

He, J., Li, W. 2009. Complex formation of cinnamaldehyde-methyl-B-cyclodextrin and musconemethyl-B-cyclodextrin by supercritical carbon dioxide processing and sealed heating method. Journal of Inclusion Phenomena and Macrocyclic Chemistry 63(1-2): 61-68.

Hwang, T.K. et al., 2019. Best Practices for New Technology Proliferation: pp. 2-3. Kunwigun Agricultural Technology Center, Gyeongbuk in Korea. Jang, Y.S., Lee, C.H., Kim, M.K., Kim, J.H., Lee, S.H., Lee, H.S. 2005. Acaricidal activity of active constituent isolated in Chamaecyparis obtusa leaves against Dermatophagoides spp. Journal of Agricultural Food Chemistry 53: 1934-1937.

Jo, Y.J., Cho, H.J., Chun, S.J., Lee, S.Y. 2015. Mechanical and Thermal Properties of Hydroxypropyl Cellulose/TEMPO-oxidized Cellulose Nanofibril Composite Films. Journal of the Korean Wood Science and Technology 43(6): 740-745.

Kang, E., Lee, S.M., Park, J.Y. 2017. Adhesion Performance of Plywoods Prepared with Different Layering Methods of Thermoplastic Resin Films. Journal of the Korean Wood Science and Technology 45(5): 559-571.

Kang, H.Y., Lee, S.S., Choi, I.G. 1993. The antifungal activity of coniferous needle oil. Forest Bioenergy 13(2): 71-77.

Kasemsan, W., Poonsub, T., Chanin, K. 2014. Morphological and Thermal Properties of LDPE/EVA Blended Films and Development of Antimicrobial
Activity in Food Packaging Film. Energy Procedia 56: $1-9$.

Kim, Y.G. 1999. Studies on Antimicrobial activities of the extractives from Magnolia. Journal of Korean Wood Science \& Technology 27(1): 105-114.

Kim, B.Y., Han, S.Y., Lee, S.Y., Kim, Y.K., Kim, N.H., Lee, S.H. 2014. Effect of Nanocellulose and Aminated Starch on Tensile and Thermal Properties of Plasticized Starch Film. Journal of the Korean Wood Science and Technology 42(4): 376-384.

Kim, G.G., Park, C.W., Yoon, T.H., Lim, N.G. 2013. Characteristics of flame retardent and mothproof conservation of microwave heated wood. Journal of the Korean Wood Science and Technology 41(3): 234-246.

Kim, Y.S. 1996. Surface electrochemical study on the fixation properties of new water-borne preservatives in red pine. Journal of the Korean Wood Science and Technology 24(4): 93-99.

Kim, C.S., Lee, J.M., Choi, C.O., Park, S.B., Eom, T.J. 2003. Chemical analysis and isolation of antibacterial compound from Ulmus species(II) Isolation and chemical structure of antibacterial compound. Journal of the Korean Wood Science and Technology 31(1): 16-21.

Kim, M.Y., Kim, Y.G., Kim, T.H., Jo, J.S., Yang, J.K. 2000. Antimicrobial activity and antioxidative activity in the extractives of Quercus dentata Thunberg. Journal of the Korean Wood Science and Technology 28(3): 42-51.

Lee, S.S., Ahn, B.J., Cho, S.T. 2010. Antimicrobial Activities of Wood Vinegar and Application as Natural Fungicides and Food Preservatives. Journal of the Korean Wood Science and Technology 38(4): 341-348.

Lee, S.H., Do, H.S., Min, K.J. 2015. Effects of essential oil from Hinoki cypress, Chamaecyparis obtusa, on physiology and behavior of flies. PloS one, 
10(12), e0143450.

Lee, S.S., Lee, H.J. 2010. Studies on antimicrobial and antioxidative activities of extracts from Magnoliaceae. Journal of the Korean Wood Science and Technology 38(6): 579-586.

Lee, H.J., Lee, S.S., Choi, D.H. 2003. Studies on biological activity of wood extractives(XII)Antimicrobial and antioxidative activities of extractives from the heartwood of Prunus sargentii(2). Journal of the Korean Wood Science and Technology 31(4): 16-23.

Lee, H.J., Lee, S.S., Choi, D.H. 2004. Studies on biological activity of wood extractives(XV)Antimicrobial and antioxidative activities of extracts from diverse familics. Journal of the Korean Wood Science and Technology 32(4): 8-17.

Liu, E.K., He, W.Q., Yan, C.R. 2014. 'White revolution' to 'white pollution'-agricultural plastic film mulch in China. Environmental Research Letters, 9(9), 091001.

Lee, S.S., Choi, D.H., Lee, H.J., Kang, H.Y. 2000. Studies on biological activity of wood extractives (II)-Antimicrobial and antioxidative compound isolated from heartwood of Zelkova serrata. Journal of the Korean Wood Science and Technology 28(2): 32-41.

Lee, S.S., Lee, H.J., Choi, D.H. 2001. Studies on biological activity of wood extractives (VII)Antimicrobial and antioxidation activities of extractives from the heartwood of Prunus sargentii. Journal of the Korean Wood Science and Technology 29(2): 140-145.

Lee, S.S., Kang, H.Y., Choi, I.G. 2002. Studies on biological activities of woody essential oils(I). Journal of the Korean Wood Science and Technology 30(1): 48-55.

Lee, S.Y., Chun, S.J., Doh, G.H., Lee, S., Kim, B.H., Min, K.S., Kim, S.C., Huh, Y.S. 2011. Prepartion of cellulose nanofibrils and their applications: High strength nanopapers and polymer composite films. Journal of Korean Wood Science \& Technology 39(3): 197-205.

Lee, W.H., Lee, K.Y., Kim, J.G. 2019. Insect repellent vinyl and tray made of Essential oil. Patent No. 1020402910000. Research and Industry-University Cooperation in Kyungpook National University

Lee, Y.K. 1994. Studies on printability of amphoteric latex-based coated paper (I). Journal of Korean Wood Science \& Technology 22(1): 80-84.

Min, K.H. 1998. Antifungal activity of the extracts of Zanthoxylum Schinifolium Sieb. Zucc. against Dermatophytes. Journal of the Korean Wood Science and Technology 26(4): 78-85.

Park, Y.G., Lee, H.J., Lee, S.S., Choi, D.H., Yeo, W.H., Oh, J.S. 2001. Studies on biological activity of wood extractives(VIII)- Antifungal activity of isoflavomoids from Sophora japonica. Journal of the Korean Wood Science and Technology 29(4): 89-96.

Peppas, N.A., Am, E.D.J. 1997. Controlled release of perfumes from polymers. II. Incorporation and release of essential oils from glassy polymers. Journal of Applied Polymer Science 66(3): 509513.

Scarascia-Mugnozza, G., Schettini, E., Vox, G., Malinconico, M., Immirzi, B., Pagliara, S. 2006. Mechanical properties decay and morphological behaviour of biodegradable films for agricultural mulching in real scale experiment. Polymer Degradation and Stability 91(11): 2801-2808.

Suppakul, P., Sonneveld, K., Bigger, S.W., Miltz, J. 2011. Loss of AM additives from antimicrobial films during storage. Journal of Food Engineering 105(2): 270-276.

Wang, S.Y., Lai, W.C., Chu, F.H., Lin, C.T., Shen, S.Y., Chang, S.T. 2006. Essential oil from the leaves 
Jin Gu KIM • Seok Gyu KANG • Md Munir MOSTAFIZ • Jeong Min LEE • Kyeong-Yeoll LEE •

Tae Kyung HWANG $\cdot$ Jin Taeg LIM $\cdot$ Soo Yeon KIM $\cdot$ Won Hee LEE

of Cryptomeria japonica acts as a silverfish (Lepisma saccharina) repellent and insecticide. Journal of Wood Science 52: 522-526.

Wang, Y.Z., Yang, K.K., Wang, X.L., Zhou, Q., Zheng, C.Y., Chen, Z.F. 2004. Agricultural application and environmental degradation of photobiodegradable polyethylene mulching films. Journal of Polymers and the Environment 12(1): 7-10.
Yang, J.K., Choi, M.S., Seo, W.T, Rinker, D.L., Han, S.W., Cheong, G.W. 2007. Chemical composition and antimicrobial activity of Chamaecyparis obtusa leaf essential oil. Fitoterapia 78: 149-152.

Yeo, H.D., Lee, H.C., Lim, B.K., Kim, H.K., Choi, S.C., Yang, J.K. 2008. Antifungal Activity of the Quercus Mongolica Extracts against Botrytis cinerea. Journal of the Korean Wood Science and Technology 36(1): 88-101. 